\title{
Multilocus heterozygosity and size: a test of hypotheses using triploid Mytilus edulis
}

\author{
ANDY R. BEAUMONT*, JENNIFER E. FAIRBROTHER \& KATHRIN HOARE \\ School of Ocean Sciences, University of Wales, Bangor, Menai Bridge, Gwynedd, LL59 5EY, Wales, U.K.
}

\begin{abstract}
Cohorts of meiosis I and meiosis II induced triploid Mytilus edulis were produced from mass matings in the laboratory and reared alongside normal diploid cohorts during 1990 and 1991. Diploid cohorts generally exhibited a significant positive correlation between multilocus heterozygosity and size. This correlation was absent or much more weakly expressed in cohorts of triploid mussels and this supports the 'associative overdominance' hypothesis rather than the 'direct involvement' hypothesis as the major explanation for the correlation. For both diploids and triploids, no correlation between heterozygosity and the coefficient of variation of size was evident and heterozygotes at single loci were not larger than homozygotes. Triallelic triploid heterozygotes were no larger than diallelic triploids. The diploid cohorts were generally in agreement with the Hardy-Weinberg model and there was no trend towards heterozygote deficiency.
\end{abstract}

Keywords: associative overdominance, heterozygosity/size, mussels, Mytilus edulis, triploids.

\section{Introduction}

Following Singh \& Zouros' (1978) original work on Malpeque Bay oysters, bivalve molluscs have continued to provide a focus for studies on the correlation of multilocus heterozygosity and fitness-related characters (e.g. Koehn \& Shumway, 1982; Foltz \& Zouros, 1984; Koehn \& Gaffney, 1984; Zouros \& Foltz, 1987; Gentili \& Beaumont, 1988; Koehn et al., 1988; Zouros et al., 1988; Hawkins et al., 1989; Volckaert \& Zouros, 1989; Gaffney et al., 1990; Beaumont, 1991) although other groups of organisms have also been studied (e.g. fish - McAndrew et al., 1986; Ferguson, 1992; salamanders - Pierce \& Mitton, 1982; frogs - McAlpine, 1993; beetles - Whitlock, 1993; deer - Leberg et al., 1990; trees - Bush et al., 1987).

Two principal hypotheses have been advanced to explain the correlation (Zouros \& Mallet, 1989; Zouros \& Pogson, 1994). First, the 'direct involvement' hypothesis proposes that features such as dominance or overdominance at the scored loci themselves are the main cause of the correlation. Koehn et al's (1988) study on Mulinia lateralis provides evidence for this. These authors reported that loci coding for enzymes involved in glycolysis or protein catabolism tended to have a greater effect on the observed correlation between heterozygosity and growth than loci coding

\footnotetext{
*Correspondence.
}

for other enzymes. They concluded that the variations in growth rate were principally determined by heterozygosity at the scored loci.

The competing hypothesis, 'associative overdominance' proposes that the correlation is the indirect result of a positive association between homozygosity at the scored locus and homozygosity for deleterious genes at loci in linkage disequilibrium with the scored locus (Zouros \& Mallet, 1989). Zouros (1993) has recently evaluated and confirmed the likely effects of inbreeding and linkage disequilibrium on the correlation but in a test using both allozymes and supposedly neutral DNA markers in the scallop Placopecten magellanicus Pogson \& Zouros (1994) were unable to provide support for the associative overdominance hypothesis.

The recent development of techniques to induce triploidy in fish and shellfish for aquacultural purposes (Beaumont \& Fairbrother, 1991; Beaumont, 1994) provides an opportunity to test these two competing hypotheses. Triploids can be produced by doubling the chromosome number in the egg following suppression of the first or second polar bodies. Depending on gene-centromere recombination rate and allele frequency at each locus (Allendorf \& Leary, 1984, and see below) much of the heterozygosity of the female may be retained in the diploidized egg and heterozygosity of the zygote may be further increased following syngamy. Apart from diallelic heterozygotes, triploids can exhibit unique triallelic heterozygous 
combinations at loci. According to the direct involvement hypothesis such genotypes might be expected in general to have at least the same, but potentially, increased fitness compared to diallelic triploids or diploids. Cohorts of triploids might therefore be expected to show a similar or stronger correlation between heterozygosity and fitness characters than cohorts of diploids. On the other hand, with three copies of a gene per genotype there is a considerably reduced likelihood of complete homozygosity for any deleterious recessive genes which might be linked to the scored loci - associative overdominance - and any correlation would therefore be weaker in triploid than in diploid cohorts. This latter feature can be demonstrated mathematically as follows.

In any population in Hardy-Weinberg equilibrium an allele $P$ of frequency $p$ will be found at a frequency of $p^{2}$ in homozygotes for that allele and at a frequency of $2 p(1-p)$ in heterozygotes for that allele. When formation of a polar body is suppressed to produce diploid eggs, the frequency of these eggs which will have the genotype $P P$ depends upon which of meiosis I or meiosis II is targeted. In both cases $P P$ females will produce only $P P$ eggs. If meiosis I is targeted, females heterozygous for $P$ will produce $P P$ eggs only if crossing-over occurs (assuming that only nonsister chromatids pass into polar body 2 , although the final conclusions are unaffected by the truth or otherwise of this assumption), when one in four of the resulting eggs will be $P P$. The frequency of $P P$ eggs produced by heterozygous $P$ females will thus be $0.25 D$, where $D$ is the frequency of crossing-over. If meiosis II is targeted half of the eggs produced by a female heterozygous for $P$ will be $P P$, unless crossing-over occurs. $P P$ eggs will thus be produced at a frequency of $0.5(1-D)$, where $D$ is again the crossing-over frequency. The proportion of $P P$ eggs in any population of diploid eggs is then a function of both the frequencies of $P$ homozygotes and heterozygotes in the maternal population and the proportions of the eggs which these females produce that are $P P$.

When meiosis I is targeted then the frequency of $P P$ eggs would be $p^{2}$ (from homozygous mothers)+ $2 p(1-p) 0.25 D$ (from heterozygous mothers) $=p^{2}+$ $0.5 D p(1-p)$, and the frequency of triple homozygote offspring for $P$, given that the frequency of $P$ in sperm from this population is $p$, would be:

$p^{3}+0.5 D p^{2}(1-p)$.

When meiosis II is targeted, the frequency of $P P$ eggs would be $p^{2}$ (from homozygous mothers) $+2 p(1-p)$ $0.5(1-D)$ (from heterozygous mothers) $=p^{2}+p(1-$ $p)(1-D)$, and the frequency of triple homozygote offspring for $P$ would be:

$p^{3}+p^{2}(1-p)(1-D)$.

The frequency of $P$ homozygotes in diploids of this offspring population will be $p^{2}$. In order for the frequency of $P$ homozygotes in meiosis I induced triploids to be greater than or equal to their frequency in diploids,

$p^{3}+0.5 D p^{2}(1-p) \geq p^{2}$

which simplifies to: $p \geq 1$.

Similarly, for meiosis II induced triploids the frequency of $P$ homozygotes will only be greater than in their diploid siblings if

$p^{3}+p^{2}(1-p)(1-D) \geq p^{2}$

which simplifies to: $p \geq 1$.

Therefore, except at monomorphic loci, the frequency of triple homozygotes in triploids will be less than the frequency of double homozygotes in diploids. Where an allele $A$ of frequency $a$ at a scorable locus is acting as a marker for an allele $B$ of frequency $b$ at a closely-linked, unscorable locus, such that $a>b$ and $B$ occurs only with $A$, in diploids the proportion of $A A$ that are also $B B$ is $b^{2} / a^{2}$. In meiosis I targeted triploids the proportion of $A A A$ that are also $B B B$ is:

$\left[b^{3}+0.5 D b^{2}(1-b)\right] /\left[a^{3}+0.5 D a^{2}(1-a)\right]$

In order for this proportion to be greater than or equal to the proportion of $B$ homozygotes to $A$ homozygotes in diploids,

$\left[b^{3}+0.5 D b^{2}(1-b)\right] /\left[a^{3}+0.5 D a^{2}(1-a)\right] \geq b^{2} / a^{2}$

which simplifies to: $\mathrm{b} \geq a$.

Similarly, in meiosis II targeted triploids the proportion of $A A A \mathrm{~s}$ that are also $B B B$ is:

$\left[b^{3}+b^{2}(1-b)(1-D)\right] /\left[a^{3}+a^{2}(1-a)(1-D)\right]$

and in order for this proportion to be greater than or equal to the proportion of $B$ homozygotes to $A$ homozygotes in diploids,

$\left[b^{3}+b^{2}(1-b)(1-D)\right] /\left[a^{3}+a^{2}(1-a)(1-D)\right] \geq b^{2} / a^{2}$

which simplifies to: $b \geq a$.

Any crossing-over between $A$ and $B$ results in either $B$ crossing to another $A$ (no effect) or to another allele at the marker locus (weakening of linkage). Any selection against $B$ alleles, as would be the case for a deleterious recessive, will also lead to a weakening of the linkage.

Therefore, as stated above, in triploids there is a considerably reduced likelihood of complete homozygosity for any deleterious recessive genes which might be linked to the scored loci (associative over- 
dominance) and any correlation between heterozygosity and fitness characters would be weaker in triploid than in diploid cohorts.

\section{Materials and methods}

Ripe Mytilus edulis were collected from moored barges in the Menai Strait, Wales in spring of 1990 and from submerged ropes off the Isle of Skye, Scotland in spring of 1991. Mussels were held in the laboratory in tanks with flowing seawater at $6^{\circ} \mathrm{C}$ until required for spawning. Spawning was induced by injecting $2 \mathrm{~mL}$ of $0.5 \mathrm{M} \mathrm{KCl}$ into the mantle cavity of individual mussels, leaving them immersed for $1 \mathrm{~h}$ at ambient temperature, and then placing them in individual glass dishes in filtered sea water (FSW, filtered to $0.2 \mu \mathrm{m}$ and UV light irradiated, $32-34 \mathrm{ppt}$ salinity) at $15-20^{\circ} \mathrm{C}$. Eggs from individual females were pooled before insemination by pooled spermatozoa from all males. Two separate trials were conducted. The numbers of contributing males and females are given in Table 1 together with the effective number of parents $\left(N_{\mathrm{e}}\right)$ calculated according to Gall (1987).

Triploids were produced following the techniques of Beaumont \& Kelly (1989) modified to handle 1.5 million eggs per treatment. In each of the two trials cytochalasin $\mathrm{B}$ (CB, $\left.0.5 \mathrm{mg} \mathrm{L}^{-1}\right)$ was used at two different times, one to target meiosis I and the other to target meiosis II. CB treatment is seldom 100 per cent effective in producing triploids (Beaumont \& Fairbrother, 1991). Thus, three cohorts of embryos were produced in each trial; (a) untreated diploid controls $(\mathrm{CON}),(\mathrm{b})$ meiosis I triploids $(\mathrm{MI} 3 \mathrm{~N})+$ diploids $(\mathrm{MI} 2 \mathrm{~N})$ and $(\mathrm{c})$ meiosis II triploids (MII3N)+diploids (MII2N). The proportions of triploids in the last two cohorts were estimated initially using chromosome counting in 3-hand 19-h-old embryos (Beaumont \& Kelly, 1989).

Fertilized eggs were allowed to develop undisturbed to the veliger larval stage $\left(72 \mathrm{~h}\right.$ at $\left.15^{\circ} \mathrm{C}\right)$ and veliger larvae were reared using standard techniques (Bayne, 1965). Larvae were divided into two pseudoreplicate cultures within each treatment and were maintained at a density of c. 10 larvae $\mathrm{mL}^{-1} \mathrm{FSW}$ in $10 \mathrm{~L}$ plastic buckets. The FSW was changed every 2 or 3 days and the larvae were fed Pavlova lutheri and Rhinomonas reticulata at 40 and 10 cells $\mu \mathrm{L}^{-1}$, respectively. Following metamorphosis, post-larvae (spat) were held in a tank in plastic cylinders closed at the base with $140 \mu \mathrm{m}$ mesh each receiving a small through-flow of seawater filtered to $75 \mu \mathrm{m}$. Care was taken during the transition between the larval and spat stages to avoid losing slow growing, late metamorphosing larvae. Spat were dripfed a mixture of concentrated microalgae to supplement nutrient arriving in the through-flow of seawater.
Table 1 Details of Mytilus edulis triploidy induction trials and loci scored

\begin{tabular}{lccccccc}
\hline Trial & Spawn date & $\mathrm{M}$ & $\mathrm{F}$ & $N_{\mathrm{e}}$ & $\begin{array}{c}\text { Unfed } \\
\text { (d) }\end{array}$ & Loci scored \\
\hline 1 & $26 / 4 / 90$ & 15 & 35 & 42 & 63 & $\begin{array}{c}\text { Gpi, Pgm, Lap, } \\
\text { Gsr }\end{array}$ \\
2 & $2 / 7 / 91$ & 24 & 30 & 53 & 147 & $\begin{array}{c}G p i, \text { Pgm, Odh, } \\
\text { Lap, Gsr, Ipp }\end{array}$ \\
& & & & & M, males; F, females; $N_{\mathrm{e}}$, effective number of parents (Gall, \\
1987); unfed, number of days with no supplementary food \\
prior to electrophoresis.
\end{tabular}

A previous study (Gentili \& Beaumont, 1988) demonstrated that the heterozygosity/growth rate correlation may be enhanced in juvenile mussels grown at high density when food supply limits growth. Therefore, for a period prior to electrophoretic analysis no supplementary microalgae were added (Table 1 ). Immediately before electrophoresis the shell length of each juvenile mussel was measured to the nearest $0.1 \mathrm{~mm}$.

Electrophoresis of juvenile diploid and triploid mussels was carried out using horizontal starch gels with a TME buffer $(0.1 \mathrm{M}$ tris, $0.1 \mathrm{~m}$ maleic acid, $0.01 \mathrm{M}$ EDTA, $0.01 \mathrm{M} \mathrm{MgCl}$ ) at $\mathrm{pH} 7.4$ or 6.0 . Enzymes stained were glucosephosphate isomerase (GPI, EC No. 5.3.1.9), phosphoglucomutase (PGM, EC No. 2.7.5.1), octopine dehydrogenase (ODH, EC No. 1.5.1.11), leucine aminopeptidase (LAP, EC No. 3.4.11.1) glutathione disulphide reductase (GSR, EC No. 1.6.4.2) and inorganic pyrophosphatase (IPP, EC No. 3.6.1.1). All stains were taken from Harris \& Hopkinson (1976) except ODH (Beaumont et al., 1980) and LAP (Beaumont et al., 1983). TME buffer at $\mathrm{pH} 6.0$ was used for the Gpi, Pgm and Odh loci and buffer at $\mathrm{pH} 7.4$ was used for the other loci.

Triploid mussels were identified on the basis of expected staining patterns. At a locus with three alleles $(A, B$ and $C)$ coding for a dimer, diallelic heterozygotes (e.g. $A B B, A C C$ ) showed a clear 1:4:4 ratio of staining intensity. The $1: 2$ ratio of staining intensity for monomeric proteins was much less clear and was not used alone to identify triploids. When present, triallelic heterozygotes $(A B C)$ could be identified at all loci.

ANOVA was used to test for significant differences in shell lengths, coefficients of variation and levels of heterozygosity of the various groups of mussels. Where several tests of the same hypothesis were made levels of significance were adjusted according to the modified Bonferroni procedure of Hochberg (1988).

Correlation between multilocus heterozygosity and size was tested for in two ways. First, the relationship 
between shell length and heterozygosity class (the number of loci at which individuals were heterozygous) was tested by linear regression. Secondly, mussels were grouped into $1 \mathrm{~mm}$ size classes and the mean number of heterozygous loci per individual was regressed against size class. Correlation coefficients and coefficients of determination were calculated for both relationships.

Additionally, for each locus in turn, the mean shell lengths of homozygotes and heterozygotes (and where appropriate, triallelic heterozygotes) were compared using ANOvA. Overall comparisons of the number of instances, across all loci, where heterozygotes exceeded the size of homozygotes were made using the sign test (Sokal \& Rohlf, 1989).

\section{Results}

In trial 1 , within the meiosis I triploid cohort, diploid mussels (MI2N) were significantly larger than triploids

Table 2 Mean shell length $\pm \mathrm{SE}$ ( $\mathrm{mm}$ ) of triploid and diploid juvenile Mytilus edulis from different treatments in triploidy trials

\begin{tabular}{llccccc}
\hline Trial & & CON & MI2N & MI3N & MII2N & MII3N \\
\hline 1 & Size & 6.9 & 7.8 & 6.4 & 6.8 & 6.2 \\
& $( \pm$ SE $)$ & $(0.2)$ & $(0.3)$ & $(0.3)$ & $(0.2)$ & $(0.2)$ \\
& $N$ & 184 & 116 & 46 & 87 & 74 \\
2 & Size & 7.6 & 8.8 & 8.7 & 7.6 & 7.3 \\
& $( \pm$ SE $)$ & $(0.1)$ & $(0.4)$ & $(0.2)$ & $(0.3)$ & $(0.1)$ \\
& $N$ & 182 & 29 & 85 & 27 & 95 \\
\hline
\end{tabular}

$N$, sample size; CON, diploid controls; MI2N and MI3N, individuals from within the meiosis I induced triploid cohort which have been electrophoretically confirmed as diploid or triploid respectively; MII2N and MII3N, individuals similarly identified from the meiosis II induced triploid cohort.
(MI3N) $\left(F_{1,160}=10.61, P<0.001\right)$ (Table 2). No other comparisons between shell length of diploids and triploids within any triploid cohort, or overall, in either trial were significant.

Comparisons between mean heterozygosity in all diploids (ALL2N) and all triploids (ALL3N) proved significant in both trials with triploids being more heterozygous (trial $1, F_{1.505}=4.76, P<0.05$; trial 2, $F_{1.416}=29.46, P<0.001$ ) (Table 3). Meiosis I triploids were significantly more heterozygous than meiosis II triploids in trial 1 but not in trial 2 (trial 1, $F_{1.118}=13.06, P<0.001 ;$ trial $2, F_{1,178}=2.84, \mathrm{NS}$ ).

Similar tests were carried out for single locus heterozygosity. In trial 1 no significant single locus effects on heterozygosity in triploids were noted. In trial 2 , only two individual loci showed a significant increase in heterozygosity in triploids; Pgm (ALL2N vs. ALL3N, $\left.F_{1,416}=12.20, \quad P<0.001\right)$ and Lap (ALL2N vs. ALL3N, $\left.F_{1,416}=20.01, P<0.001\right)$.

For all groupings in trial 1 the correlations between the shell length of individuals and the number of loci at which they were heterozygous were positive, significantly so at the table-wide level (Hochberg, 1988) in the control diploids and in diploids overall (CON and ALL2N, Table 4). There were both negative and positive correlations in trial 2 none of which was significant table-wide (Table 4).

The coefficients of determination for trial 1 controls and diploids overall were 0.042 and 0.046 , respectively, indicating that $c .4$ per cent of the variation in size among individuals was attributable to the measured variation in multilocus heterozygosity.

Table 5 and Fig. 1 show the relationship between mean number of heterozygous loci per individual (mean heterozygosity) and shell length class (1 mm size classes). Although there are significant positive correlations indicated for controls, the MI2N group, overall diploids and overall triploids, only the results for the MI $2 \mathrm{~N}$ group and the diploids overall in trial 1 are

Table 3 Mean percentage ( $\pm \mathrm{SE}$ ) of heterozygous loci per individual juvenile Mytilus edulis from triploidy trials

\begin{tabular}{cccccccc}
\hline Trial & CON & MI2N & MI3N & MII2N & MII3N & ALL2N & ALL3N \\
\hline 1 & 59.3 & 68.8 & 75.5 & 64.9 & 63.5 & 63.4 & 68.1 \\
& $(1.7)$ & $(1.9)$ & $(2.9)$ & $(1.8)$ & $(1.9)$ & $(1.1)$ & $(1.7)$ \\
$N$ & 184 & 116 & 46 & 87 & 74 & 387 & 120 \\
2 & 39.2 & 49.4 & 47.1 & 40.1 & 50.7 & 40.6 & 49.0 \\
& $(1.3)$ & $(2.4)$ & $(1.6)$ & $(2.7)$ & $(1.5)$ & $(1.1)$ & $(1.1)$ \\
$N$ & 182 & 29 & 85 & 27 & 95 & 238 & 180 \\
\hline
\end{tabular}

Abbreviations as Table 2. ALL2N comprises data from CON, MI2N and MII2N; ALL3N includes data from MI3N and MII3N. 
Table 4 Regression of shell length ( $\mathrm{mm}$ ) of individual juvenile diploid and triploid Mytilus edulis on the number of loci at which they were heterozygous

\begin{tabular}{lllllcccr}
\hline Trial & & CON & MI2N & MI3N & MII2N & MII3N & ALL2N & ALL3N \\
\hline 1 & $b$ & 0.465 & 0.747 & 0.380 & 0.197 & 0.262 & 0.566 & 0.347 \\
& $r$ & 0.205 & 0.210 & 0.145 & 0.063 & 0.100 & 0.214 & 0.148 \\
& $F$ & 7.95 & 5.21 & 0.94 & 0.31 & 0.70 & 18.73 & 2.61 \\
& $P$ & $* *$ & $*$ & NS & NS & NS & $* * *$ & NS \\
2 & $b$ & -0.004 & 0.874 & -0.049 & -0.244 & -0.007 & 0.134 & -0.125 \\
& $r$ & 0.000 & 0.334 & 0.000 & 0.134 & 0.0000 & 0.071 & 0.055 \\
& $F$ & 0.00 & 3.62 & 0.03 & 0.46 & 0.00 & 1.27 & 0.53 \\
& $P$ & NS & NS & NS & NS & NS & NS & NS \\
\hline
\end{tabular}

$b$, slope of regression; $r$, correlation coefficient; $F$, variance ratio, probabilities based on single tests; ${ }^{*} 0.05>P>0.01$, ${ }^{* *} 0.01>P>0.001,{ }^{* * *} P<0.001, \mathrm{NS}=$ not significant. For other abbreviations see Table 2.

Table 5 Regression of average heterozygosity (mean number of heterozygous loci per individual) on shell length class (1 $\mathrm{mm}$ size classes) for juvenile triploid and diploid Mytilus edulis

\begin{tabular}{|c|c|c|c|c|c|c|c|c|}
\hline Trial & & $\mathrm{CON}$ & $\mathrm{MI} 2 \mathrm{~N}$ & MI3N & MII2N & MII3N & ALL2N & ALL3N \\
\hline \multirow[t]{4}{*}{1} & $b$ & 0.078 & 0.070 & 0.037 & -0.033 & 0.063 & 0.076 & 0.054 \\
\hline & $r$ & 0.682 & 0.767 & 0.396 & 0.303 & 0.648 & 0.809 & 0.725 \\
\hline & $F$ & 6.25 & 14.29 & 1.30 & 0.81 & 4.35 & 18.86 & 8.85 \\
\hline & $P$ & $*$ & $* *$ & NS & NS & NS & $* * *$ & $*$ \\
\hline \multirow[t]{4}{*}{2} & $b$ & -0.027 & 0.108 & -0.034 & -0.027 & 0.053 & 0.062 & -0.052 \\
\hline & $r$ & 0.377 & 0.628 & 0.283 & 0.195 & 0.404 & 0.690 & 0.610 \\
\hline & $F$ & 0.99 & 2.61 & 0.52 & 0.16 & 0.98 & 6.35 & 4.15 \\
\hline & $P$ & NS & NS & NS & NS & NS & $*$ & NS \\
\hline
\end{tabular}

Abbreviations as Tables 2 and 4.

significant table-wide (Table 5) and the coefficients of determination for these two groups were 0.558 and 0.655 , respectively. There are no significant correlations table-wide in trial 2 but, as a single test, a significant positive correlation is noted for the ALL2N group.

There was no apparent trend for decreased coefficient of shell length variation with increased heterozygosity amongst triploids or diploids in either trial (Table 6) and ANova of pooled data from both trials confirms this $\left(2 \mathrm{~N}, F_{3.621}=0.42\right.$, NS; $3 \mathrm{~N}, F_{2.289}=0.59$, NS).

Data were further analysed by comparing the mean shell length of heterozygotes with homozygotes at individual loci within each cohort. In trial 1 diploid heterozygotes were significantly larger than homozygotes at the Lap and Pgm loci in the controls and at the $G s r$ locus in the MI2N cohort (table-wide $P<0.05$ ) but there were no such differences in diploids in trial 2 . For triploids, only Ipp heterozygotes were significantly smaller than homozygotes in the MII $3 \mathrm{~N}$ cohort of trial
2 (table-wide $P<0.05$ ). For diploids and triploids overall, across all loci and all cohorts in both trials (Table 7), there was no trend for single locus heterozygotes to be larger than homozygotes.

Triploid groups were tested to determine whether triallelic heterozygotes at a locus differed in size from diallelic heterozygotes (Table 8). In no cases were the differences significant table-wide although in certain of the tests numbers of triallelic heterozygous individuals were small.

The genotype frequencies of the control diploid cohorts were tested against the Hardy-Weinberg model (Table 9). There were two significant deviations showing heterozygote excess (-ve $F_{\text {is }}$ ) in trial 1 ( Lap, $G s r)$ and one significant deficiency of heterozygotes $\left(+\right.$ ve $\left.F_{\text {is }}\right)$ in trial $2(P g m)$. Most loci tested therefore were in good agreement with the Hardy-Weinberg model and there was certainly no evidence of a general trend towards heterozygote deficiencies (only 2 of 10 values of $F_{\text {is }}$ were positive). 
(a)

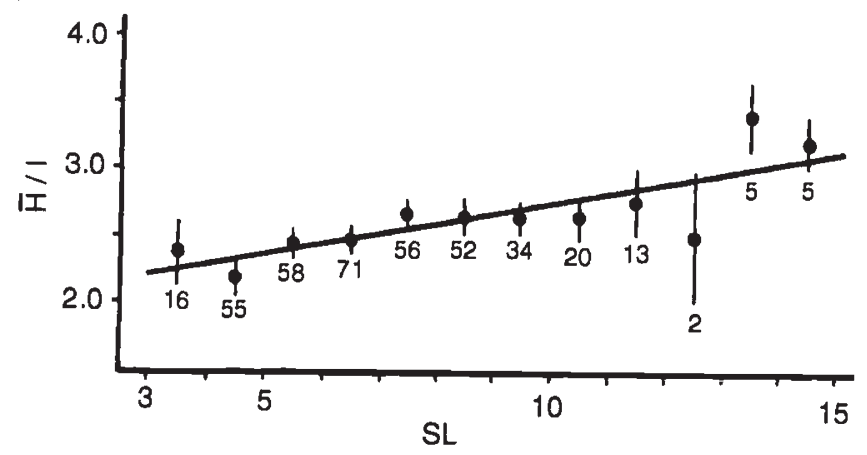

(c)

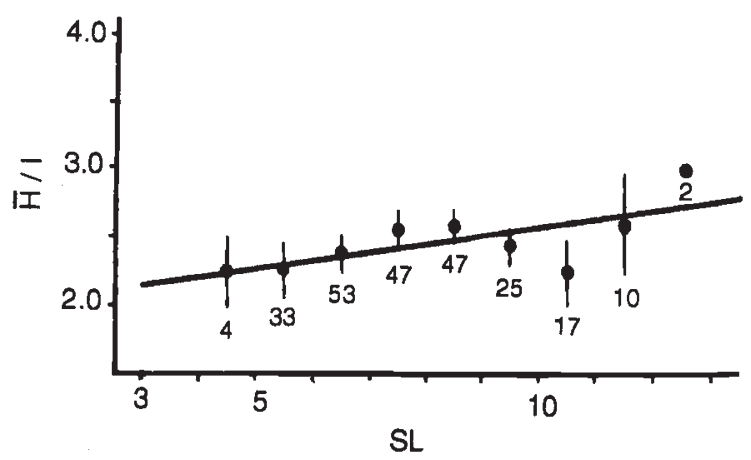

(b)

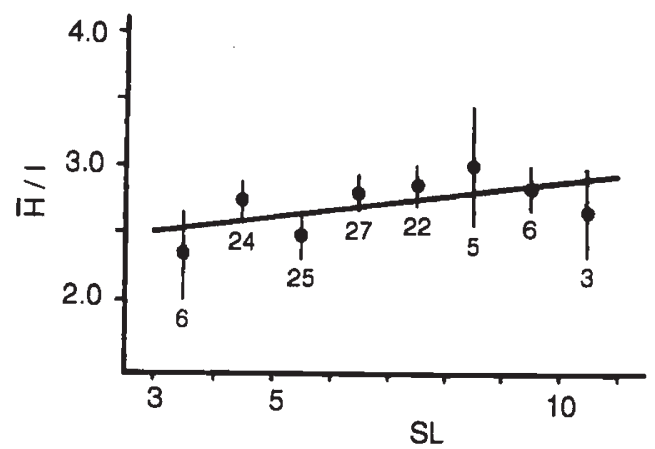

(d)

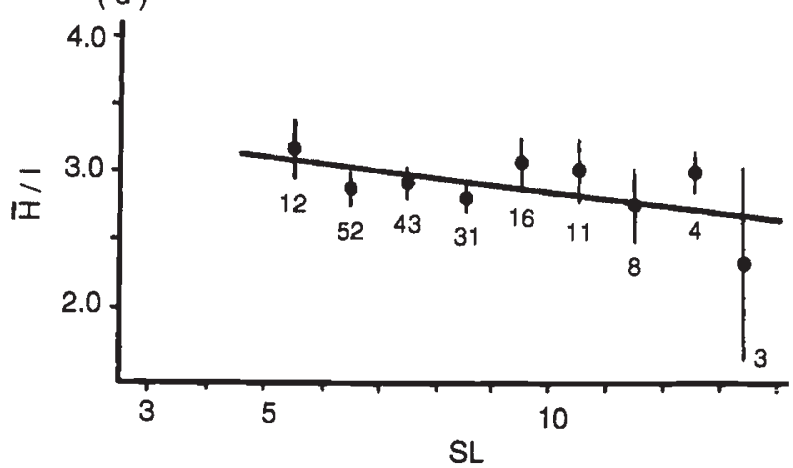

Fig. 1 The relationship between the mean number of heterozygous loci per individual $(\hat{\mathrm{H}} / \mathrm{I})$ and shell length class $(\mathrm{SL}$ in $\mathrm{mm})$ in diploid and triploid cohorts of Mytilus edulis. Trial 1; (a) diploids (ALL2N), (b) triploids (ALL3N) and trial 2; (c) diploids (ALL2N), (d) triploids (ALL3N); see Table 5 for details and for significances of correlation coefficients. Vertical lines through the means indicate standard errors and numbers of individuals are indicated for each shell length class.

Table 6 Relationship between coefficient of variation (CV) of shell length (SL, mm) and number of loci heterozygous $(\mathrm{NH})$ in diploid and triploid Mytilus edulis

\begin{tabular}{|c|c|c|c|c|c|c|c|c|c|}
\hline \multirow[b]{2}{*}{ Trial } & \multirow[b]{2}{*}{$N H$} & \multicolumn{4}{|c|}{ ALL2N } & \multicolumn{4}{|c|}{ ALL3N } \\
\hline & & 1 & 2 & 3 & 4 & 1 & 2 & 3 & 4 \\
\hline 1 & $\begin{array}{l}N \\
\mathrm{SL} \\
\mathrm{CV}\end{array}$ & $\begin{array}{r}32 \\
6.3 \\
33.5\end{array}$ & $\begin{array}{r}152 \\
6.8 \\
28.9\end{array}$ & $\begin{array}{r}155 \\
7.5 \\
32.8\end{array}$ & $\begin{array}{c}48 \\
7.9 \\
31.2\end{array}$ & $\begin{array}{l}- \\
-\end{array}$ & $\begin{array}{c}48 \\
6.0 \\
24.5\end{array}$ & $\begin{array}{r}54 \\
6.6 \\
31.5\end{array}$ & $\begin{array}{r}18 \\
6.5 \\
20.9\end{array}$ \\
\hline 2 & $\begin{array}{l}N \\
\mathrm{SL} \\
\mathrm{CV}\end{array}$ & $\begin{array}{r}42 \\
7.5 \\
25.5\end{array}$ & $\begin{array}{c}83 \\
7.7 \\
19.9\end{array}$ & $\begin{array}{c}79 \\
7.9 \\
23.6\end{array}$ & $\begin{array}{r}34 \\
7.9 \\
20.9\end{array}$ & $\begin{array}{c}8 \\
8.4 \\
37.8\end{array}$ & $\begin{array}{r}43 \\
7.9 \\
19.0\end{array}$ & $\begin{array}{r}88 \\
8.1 \\
23.7\end{array}$ & $\begin{array}{r}41 \\
7.7 \\
21.9\end{array}$ \\
\hline Overall & $\mathrm{CV}$ & 26.4 & 24.2 & 27.1 & 23.0 & - & 21.1 & 26.6 & 21.0 \\
\hline
\end{tabular}

$N$, number of individuals; - , insufficient numbers, pooled with next heterozygote class. 'Overall' is the mean of the CVs from all of the cohorts in both trials.

\section{Discussion}

Before discussing the results it is necessary to consider the argument that the physiology of triploid mussels might be so different from that of diploids that the use of triploids to test hypotheses concerning the correlation between multiple locus heterozygosity and physiological parameters may not be valid. Cell nuclei of triploid shellfish are approximately 1.3 times the diameter of nuclei in diploids (Allen et al. 1989; 
Ekaratne \& Davenport, 1993) but there are no published reports indicating that overall cell size in somatic tissue is increased in triploid shellfish.

If somatic tissue cells were generally larger in triploids than in diploids but the numbers of cells were similar then body size of triploids should be greater than diploids. There are very few studies on body size of natural populations of triploids living sympatrically with conspecific diploids and the results of such studies are equivocal. For example, in the rotifer Euchlanis dilitata naturally occurring triploids grow faster and are

Table 7 Single locus heterozygosity and size in triploid and diploid Mytilus edulis

\begin{tabular}{lrrrrrrr}
\hline & \multicolumn{3}{c}{$2 \mathrm{~N}$} & & & \multicolumn{2}{c}{$3 \mathrm{~N}$} \\
\cline { 2 - 3 } \cline { 5 - 7 } Locus & + & - & & & + & - & $=$ \\
\hline Pgm & 5 & 1 & 0 & 2 & 2 & 0 \\
Gpi & 2 & 3 & 1 & 1 & 2 & 1 \\
Lap & 3 & 3 & 0 & 3 & 1 & 0 \\
Gsr & 5 & 1 & 0 & 2 & 1 & 1 \\
Odh & 2 & 1 & 0 & 0 & 2 & 0 \\
Ipp* & 0 & 3 & 0 & 0 & 1 & 0 \\
Total & 17 & 12 & 1 & 8 & 9 & 2 \\
\hline
\end{tabular}

Number of instances where the mean shell length of heterozygotes at a locus is greater than $(+)$, equal to $(=)$ or less than $(-)$ the mean shell length of homozygotes. Diploids $(2 \mathrm{~N})$ include 3 groups, CON, MI2N and MII2N, from each trial and triploids $(3 \mathrm{~N})$ include 2 groups, MI3N and MII3N, from each trial. *All individuals in the MI3N group were homozygous at the Ipp locus. larger as adults than sympatric diploids (Walsh \& Zhang, 1992) while in the fish Poeciliopsis monachalucida the reverse is true, triploids generally being smaller than diploids (Schultz, 1982).

If cell size is similar in triploids and diploids then the important variable is the ratio between the nuclear and the cytoplasmic contents of the cell. According to Cavalier-Smith (1978), natural selection operates strongly on organisms to determine their cell size and their developmental rates because these two features are inversely related. As larger cells require larger nuclei, selection for a particular cell volume will secondarily select for a corresponding nuclear volume. The implication is that the nucleus/cytoplasm size ratio

Table 8 Comparisons between mean shell lengths of triallelic and diallelic triploid heterozygote Mytilus edulis juveniles

\begin{tabular}{lcccc}
\hline & \multicolumn{2}{c}{ Trial 1 } & \multicolumn{2}{c}{ Trial 2 } \\
\cline { 2 - 3 } \cline { 5 - 5 } Locus & MI3N & MII3N & MI3N & MII3N \\
\hline Pgm & $-(32,6)^{*}$ & $-(31,2)$ & $+(41,30)$ & $+(49,31)$ \\
Gpi & $(\mathrm{a})$ & $-(32,1)$ & $+(55,5)$ & $-(67,2)$ \\
Lap & $+(32,2)$ & $+(46,15)$ & $+(41,34)$ & $-(61,12)$ \\
Gsr & $(\mathrm{a})$ & $-(57,5)$ & $(\mathrm{a})$ & $+(43,1)$ \\
\hline
\end{tabular}

Mean length of triallelic heterozygotes larger than $(+)$ or smaller than ( - ) diallelic heterozygotes. Sample sizes in brackets, number of diallelic heterozygotes followed by number of triallelics. (a), no triallelic heterozygotes; *, significant at $P<0.05$ as an individual test but not significant table-wide. No Odh or Ipp triallelic heterozygotes were observed.

Table 9 Population genetic data for the control diploid Mytilus edulis cohorts in trials 1 and 2

\begin{tabular}{cccccccc}
\hline Trial & Locus & $N_{\text {eff }}$ & $H_{\mathrm{o}}$ & $H_{\mathrm{e}}$ & $F_{\text {is }}$ & d.f. & $\chi^{2}$ \\
\hline \multirow{2}{*}{1} & $G p i$ & 1.146 & 0.350 & 0.318 & -0.101 & 1 & 2.34 \\
& Lap & 2.841 & 0.826 & 0.648 & -0.272 & 3 & $36.24^{* * *}$ \\
& Pgm & 2.055 & 0.534 & 0.501 & -0.050 & 3 & 6.38 \\
& Gsr & 2.152 & 0.599 & 0.527 & -0.117 & 6 & $24.01^{* * *}$ \\
2 & Gpi & 2.603 & 0.587 & 0.589 & 0.003 & 3 & 2.11 \\
& Lap & 2.102 & 0.563 & 0.519 & -0.080 & 3 & 3.89 \\
& Pgm & 4.769 & 0.673 & 0.774 & -0.145 & 6 & $28.36^{* * *}$ \\
& $G s r$ & 1.562 & 0.333 & 0.332 & -0.036 & 1 & 0.00 \\
& Odh & 1.058 & 0.056 & 0.054 & -0.019 & 3 & 0.02 \\
& Ipp & 1.043 & 0.042 & 0.041 & -0.019 & 1 & 0.00 \\
\hline
\end{tabular}

$N_{\text {eff }}$, effective number of alleles $\left(1 / \Sigma x_{i}^{2}\right.$, where $x_{i}$ is the $i$ th allele frequency); $H_{0}$, observed heterozygosity; $H_{\mathrm{e}}$, expected heterozygosity; $F_{\text {is }}, F$-statistic of Wright (1965) calculated using the correction of Weir \& Cockerham $(1984) ; \chi^{2}$, goodness of fit to Hardy-Weinberg model with d.f. as indicated, ${ }^{* * *} P<0.001$. 
in triploids will not be ideal if the cell size is the same as diploids.

In certain polyploid plants there may be highly significant intraspecific differences in the size of the nucleus which can apparently be caused by variations in the amount of heterochromatin or the frequency of repeated DNA sequences (Cavallini \& Natali, 1991). However, the quantity of DNA in nuclei of somatic cells of triploid shellfish individuals is consistently very close to 1.5 times that of diploids - quantification of DNA content is one of the best methods for distinguishing diploids and triploids - suggesting that such a mechanism does not operate to any great extent in triploid shellfish.

The importance of the nucleus/cytoplasm size ratio in development is underlined by Guo \& Allen's (1994) demonstration that viable tetraploid Pacific oysters (Crassostrea gigas) can be produced by ploidy manipulation of triploid eggs whereas all previous attempts with diploid eggs had been unsuccessful (Beaumont \& Fairbrother, 1991). Triploid eggs are larger than diploid eggs (Guo \& Allen, 1994) and the theory is that the extra cytoplasm present in such eggs provides a more suitable nucleus/cytoplasm size ratio allowing normal development of a tetraploid embryo.

There have been a number of comparisons of the physiological energetics of artificially produced triploid and diploid fish and shellfish. Mason et al. (1988), in their thorough study of juvenile Mya arenaria, demonstrated no consistent energetic differences between triploids and diploids although there was a tendency for diploids to be more 'robust' while the variances around means for the measured characters (e.g. oxygen uptake, filtration rate, tissue weight) were always lower in triploids. Similarly, Ekaratne \& Davenport (1993) could find no differences in oxygen uptake rates between triploid and diploid juvenile Manila clam (Tapes philippinarum) although, as expected, the considerably reduced gametogenesis in older clams did result in some differences between the energetics of adult triploids and diploids. Published results documenting growth rates of triploid and diploid shellfish up to maturity are variable; a few studies show significant larval or juvenile growth improvement in triploids while most do not (Beaumont \& Fairbrother, 1991). In studies on fish there are generally no significant differences between juvenile diploids and triploids in oxygen consumption or other physiological parameters such as growth (Thorgaard \& Allen, 1987; Benfey, 1991; Thorgaard, 1992).

Although Mason et al. (1988) state that it seems reasonable to assume that triploidy per se poses energetic and metabolic difficulties on a cellular level not experienced by diploids', all the evidence actually suggests that triploidy induction does not produce organisms which are physiologically different from diploid controls prior to gametogenesis. We are therefore satisfied that it is legitimate to use triploid shellfish to test the competing explanatory hypotheses for the correlation between multilocus heterozygosity and physiological parameters.

The data on overall heterozygosity levels and mean sizes of mussels show in both trials that triploids are significantly more heterozygous than diploids but that, at the juvenile stage, triploids are not significantly larger than diploids (Tables 2 and 3). This is in agreement with studies on other bivalves (Crassostrea virginica, Stanley et al., 1981, 1984; Mya arenaria, Mason et al., 1988) where significantly higher heterozygosity in triploids was not accompanied by any significant difference between diploids and triploids in their size at the juvenile stage. However, it is worth noting that the microhabitats experienced by individual mussel spat settled together in clumps, a common occurrence in our rearing system (and in the wild), can be very different and can lead to extensive environmentally induced differences in growth rate between mussel groups. Furthermore, since there was no replication at this stage and the spat density was not rigidly controlled, direct size comparisons between diploid and triploid groups should be treated with some caution.

The demonstration of significant positive correlations between multilocus heterozygosity and size class (Table 5, Fig. 1) in groups of diploid mussels in at least one of the trials is important. The strongest correlations are very similar to those reported for the wild mussel populations studied by Koehn \& Gaffney (1984) and Zouros et al. (1988). Earlier studies have indicated that the presence of a heterozygosity/growth correlation (or its detection) may depend upon the genetic background of the population analysed. Offspring from single families or from resticted parentage seldom show a correlation (Gaffney \& Scott, 1984; Beaumont, 1991). In this study the effective population size of the progenitors was 42.0 and 53.3 for trials 1 and 2, respectively, and this supports Beaumont's (1991) suggestion that more than 40 effective progenitors are probably required before any correlation is likely to be detected in the resulting offspring. It is also important to note that the correlations are significant even though only four loci were sufficiently polymorphic to be used in trial 1 .

It is clear in both trials that comparison between the strength of the correlation in all diploid (ALL2N) and all triploid (ALL3N) groups is always in the same direction: the positive heterozygosity/growth correlation is stronger in the diploid than in the triploid groups (Tables 4 and 5, Fig. 1). 
In studies such as this, weak correlations are likely to be more easily detected and more convincingly demonstrated when sample sizes are large. In both trials the sample sizes of triploid groups were generally smaller than diploid groups and it could be argued that this might contribute to the apparent differences in strength of the correlation between triploids and diploids. While this might apply to the MI3N and the MII3N groups separately, the total triploid samples (ALL3N) in either trial consist of well over 100 individuals and several of the published studies in the literature have demonstrated significant positive correlations with sample sizes of $c$. 100. We therefore do not believe that the differences in the strength of the correlation in diploids and triploids are due to differences in sample size.

We conclude therefore that our data provide support for the associative overdominance hypothesis rather than the direct involvement hypothesis as the major explanation for the heterozygosity/growth correlation in mussels.

If cohorts of triploid organisms do not exhibit a strong positive heterozygosity/growth correlation because of associative overdominance then the logic of our argument would predict an even smaller likelihood of a correlation being evident in a population of tetraploids. Salmonids as a group have undergone a tetraploidization event relatively recently in their evolutionary history and several studies have demonstrated significant positive correlations between multilocus heterozygosity and physiological parameters in salmonids (e.g. Leary et al., 1983; Ferguson, 1992). However, there has been functional diploidization in the salmonid lineage with the formation of divalent rather than tetravalent sets of chromosomes at meiosis with duplicate loci either diverging from each other (producing electrophoretically distinct proteins) or becoming silenced (Ferguson, 1980). They are therefore effectively diploid, rather than tetraploid, organisms.

The grass Dactylis glomerata, on the other hand, is an autopolyploid tetrasomic species with tetravalents forming at meiosis and Tomekpe \& Lumaret (1991) have shown that multilocus heterozygosity has a significant positive correlation with leaf weight and flower head (panicle) number in this species. This would not be expected under the associative overdominance theory. Furthermore, at two loci, the performance of some characters improved regularly from monogenics (homozygotes for one allele) to tetragenics (heterozygotes for four alleles) and they conclude that for these loci, at least, there is a direct involvement of heterozygosity with performance characters. Our data suggest that no growth advantage was evident in triallelic heterozygous mussels relative to diallelic heterozygotes at the Pgm, Gpi, Lap or Gsr loci (Table 8 ) although the numbers of triallelic heterozygotes are quite small in some of the comparisons.

Other single locus tests (Table 7) indicate that at no loci were heterozygotes consistently significantly larger than homozygotes in either trial. In other studies on bivalves where a significant positive association between heterozygosity and size was detected, at least some significant single locus effects have usually also been observed (Koehn \& Gaffney, 1984; Zouros et al., 1988; Gaffney et al., 1990).

In many, but not all, data sets from bivalves which show a significant positive heterozygosity/growth correlation, there is also a negative correlation between heterozygosity and the coefficient of variation of the measured parameter. Multilocus heterozygotes generally have a lower coefficient of variation than multilocus homozygotes. This feature is not evident in our data (Table 6).

Deficiencies of heterozygotes against HardyWeinberg equilibrium (indicated by + ve values of Wright's (1965) $F_{\text {is }}$ ) are often detected in natural populations of marine bivalve molluscs (Zouros \& Foltz, 1984) and often co-occur in data sets which show the heterozygosity/growth correlation. Analysis of the control diploids from both trials (Table 9) reveals no consistent pattern of heterozygote deficiency in either data set. In fact, in trial 1 there was a significant excess of heterozygotes at the Lap and Gsr loci. This study provides further evidence that although the two phenomena of heterozygote deficiency and a heterozygosity/growth correlation often co-occur in the same data sets they do not share a single cause (Gaffney et al., 1990; Beaumont, 1991; Gaffney, 1994).

\section{Acknowledgements}

We are grateful to the Natural Environment Research Council for funding this study under Grant GR3/7401 to ARB. We thank Dr J. Goudet and Dr. C. J. Gliddon for the use of, and assistance with, their 'FSTAT' program.

\section{References}

ALLEN, S. K., Jr., DOWNING, S. L. AND CHEW, K. K. 1989. Hatchery Manual for Producing Triploid Oysters. Washington Sea Grant Program, University of Washington Press, Seattle, WA.

ALLENDORF, F. W. AND LEARY, R. F. 1984. Heterozygosity in gynogenetic diploids and triploids estimated by genecentromere recombination rates. Aquaculture, 43, 413-420.

BAYNE, B. L. 1965. Growth and the delay of metamorphosis of the larvae of Mytilus edulis (L). Ophelia, 2, 1-47. 
BEAUMONT, A. R. 1991. Genetic studies of laboratory reared mussels, Mytilus edulis: heterozygote deficiencies, heterozygosity and growth. Biol. J. Linn. Soc., 44, 273-285.

BEAUMONT, A, R. 1994. The application and relevance of genetics in aquaculture. In: Beaumont, A. R. (ed.) Genetics and Evolution of Aquatic Organisms, pp. 467-486. Chapman and Hall, London.

BEAUMONT, A. R. AND FAIRBROTHER, J. E. 1991. Ploidy manipulation in molluscan shellfish: a review. J. Shellfish Res., 10, $1-18$.

BEAUmont, A. R. AND Kelly, K. S. 1989. Production and growth of triploid Mytilus edulis larvae. J. Exp. Mar. Biol. Ecol., 132, 69-84.

BEAUMONT, A. R. , BEVERIDGE, C. M. AND BUDD, M. D. 1983. Selection and heterozygosity within single families of the mussel Mytilus edulis (L. ). Mar. Biol. Lett., 4, 151-161.

BEAUMONT, A. R., DAY, T. R. AND GADE, G. 1980 . Genetic variation at the octopine dehydrogenase locus in the adductor muscle of Cerastoderma edule (L.) and six other bivalve species. Mar. Biol. Lett., 1, 137-148.

BENFEY, T. J. 1991. The physiology of triploid salmonids in relation to aquaculture. In: Pepper, V. A. (ed.) Proceedings, Atlantic Canada Workshop on Methods for Production of Non-maturing Salmonids, Feb. 19-21, 1991, Nova Scotia, pp. 73-80. Dept. of Fisheries and Oceans, Newfoundland.

BUSH, R. M., SMOUSE, P. E. AND LEDIG, F. T. 1987. The fitness consequences of multiple-locus heterozygosity: the relationship between heterozygosity and growth rate in pitch pine (Pinus rigida Mill.). Evolution, 41, 787-798.

CAVALIER-SMITH, T. 1978. Nuclear volume control by nucleoskeletal DNA, selection for cell volume and cell growth rate, and the solution to the DNA C-value paradox. J. Cell. Sci., 34, 247-287.

CAVALLINI, A. AND NATALI, L. 1991. Intraspecific variation of nuclear DNA content in plant species. Caryologia, 44, 93-107.

EKARATNE, S. U. K. AND DAVENPORT, J. 1993. The relationships between the gametogenetic status of triploids or diploids of Manila clams, Tapes philippinarum, and their oxygen uptake and gill particle transport. Aquaculture, 117, 335-349.

FERGUSON, A. 1980. Biochemical Systematics and Evolution. Blackie, Glasgow.

FERGUSON, M. M. 1992. Enzyme heterozygosity and growth in rainbow trout: genetic and physiological explanations. Heredity, 68, 115-122.

FOLTZ, D. W. AND ZOUROS, E. 1984. Enzyme heterozygosity in the scallop Placopecten magellanicus (Gmelin) in relation to age and size. Mar Biol. Lett., 5, 255-263.

GAFFNEY, P. M. 1994. Heterosis and heterozygote deficiencies in marine bivalves: more light? In: Beaumont, A. R. (ed.) Genetics and Evolution of Aquatic Organisms, pp. 146-153. Chapman and Hall, London.

GAFFNEY, P. M. AND SCOTT, T. M. 1984. Genetic heterozygosity and production traits in natural and hatchery populations of bivalves. Aquaculture, 42, 298-302.

GAFFNEY, P. M., SCOTT, T. M., KOEHN, R. K. AND DIEHL, W. J. 1990. Interrelationships of heterozygosity, growth rate and heterozygote deficiencies in the coot clam, Mulinia lateralis. Genetics, 124, 687-699.
GALL, G. A. E. 1987. Inbreeding. In: Ryman, N. and Utter, F. (eds) Population Genetics and Fishery Management, pp. 47-87. University of Washington Press, Seattle, WA.

GENTILI, M. R. AND BEAUMONT, A. R. 1988. Environmental stress, heterozygosity and growth rate in Mytilus edulis. J. Exp. Mar. Biol. Ecol., 120, 145-153.

GUo, X. AND ALLEN, S. K., Jr. 1994. Viable tetraploids in the Pacific oyster (Crassostrea gigas Thunberg) produced by inhibiting polar body 1 in eggs from triploids. Mol. Mar. Biol. Biotech., 3, 42-50.

HARRIS, H. AND HOPKINSON, D. A. 1976. Handbook of Enzyme Electrophoresis in Human Genetics. North Holland Pub., Amsterdam.

HAWKINS, A. J. S., BAYNE, B. L., DAY, A. J., RUSIN, J. AND WORRALL, C. M. 1989. Genotype-dependent interrelations between energy metabolism, protein metabolism and fitness. In: Ryland, J. S. and Tyler, P. A. (eds) Reproduction, Genetics and Distributions of Marine Organisms, pp. 283-292. Olsen and Olsen, Fredensborg.

HOCHBERG, Y. 1988. A sharper Bonferroni procedure for multiple tests of significance. Biometrica, 75, 800-802.

KOEHN, R. K. AND GAFFNEY, P. M. 1984. Genetic heterozygosity and growth rate in Mytilus edulis. Mar. Biol., 82, 1-7.

KOEHN, R. K., DIEHL, W. J. AND SCOTT, T, M. 1988. The differential contribution by individual enzymes of glycolysis and protein catabolism to the relationship between heterozygosity and growth rate in the coot clam, Mulinia lateralis. Genetics, 118, 121-130.

KOEHN, R. K. AND SHUMWAY, S. E. 1982. A genetic/physiological explanation for differential growth rate among individuals of the American oyster, Crassostrea virginica (Gmelin). Mar. Biol. Lett., 3, 35-42.

LEARY, R. F., ALLENDORF, F. W. AND KNUDSEN, K. L. 1983. Developmental stability and enzyme heterozygosity in rainbow trout. Nature, 301, 71-72.

LEBERG, P. L., SMITH, M. H. AND RHODES, O. E. 1990. The association between heterozygosity and growth of deer fetuses is not explained by effects of the loci examined. Evolution, 44, 454-458.

MASON, K. M., SHUMWAY, S. E., ALLEN, S. K., Jr. AND HIDU, H. 1988. Induced triploidy in the soft-shelled clam Mya arenaria: energetic implications. Mar. Biol., 98, 519-528.

McAlPINE, S. 1993. Genetic heterozygosity and reproductive success in the green treefrog, Hyla cinerea. Heredity, 70, $553-558$.

McANDREW, B. J., WARD, R. D. AND BEARDMORE, J. A. 1986. Growth rate and heterozygosity in the plaice, Pleuronectes platessa. Heredity, 57, 171-180.

PIERCE, B. A. AND MITTON, J. B. 1982. Allozyme heterozygosity and growth rate in the tiger salamander Ambystoma tigrinum. J. Hered., 73, 250-253.

POGSON, G. H. AND zouros, E. 1994. Allozyme and RFLP heterozygosities as correlates of growth rate in the scallop Placopecten magellanicus: a test of the associative overdominance hypothesis. Genetics, 137, 221-231.

sCHUltz, R. J. 1982. Competition and adaptation among diploid and polyploid clones of unisexual fishes. In: Dingle, $\mathrm{N}$ and Hegmann, J. P. (eds) Evolution and Genetics of Life Histories, pp. 103-119. Springer Verlag, New York. 
SINGH, S. M. AND ZOUROS, E. 1978. Genetic variation associated with growth rate in the American oyster (Crassostrea virginica). Evolution, 32, 342-353.

SOKAL, R. R. AND RoHLF, F. J. 1989. Biometry, 3rd edn. W. H. Freeman and Co., San Francisco.

Stanley, J. G., Allen, S. K. AND hidu, H. 1981. Polyploidy induced in the American oyster, Crassostrea virginica with cytochalasin B. Aquaculture, 23, 1-10.

STANLEY, J. G., HIDU, H. AND ALLEN, S. K. 1984. Growth of American oysters increased by polyploidy induced by blocking meiosis I but not meiosis II. Aquaculture, 37, 147-155.

THORGAARD, G. H. 1992. Application of genetic technologies to rainbow trout. Aquaculture, 100, 85-97.

THORGAARD, G. H. AND ALLEN, S. K. 1987. Chromosome manipulation and markers in fishery management. In: Ryman, N. and Utter, F. (eds) Population Genetics and Fishery Management, pp. 319-331. University of Washington Press, Seattle, WA.

TOMEKPE, K. AND LUMARET, R. 1991. Association between quantitative traits and allozyme heterozygosity in a tetrasomic species: Dactylis glomerata. Evolution, 45, 359-370.

VOLCKAERT, F. AND zouros, E. 1989. Allozyme and physiological variation in the scallop Placopecten magellanicus and a general model for the effects of heterozygosity on fitness in marine molluscs. Mar. Biol., 103, 51-61.

WALSH, E. J. AND ZHANG, L. 1992. Polyploidy and body size variation in a natural population of the rotifer Euchlanis dilatata. J. Evol. Biol., 5, 345-353.

WEIR, B. S. AND COCKERHAM, C. C. 1984 . Estimating F-statistics for the analysis of population structure. Evolution, 38, $1358-1370$.
WHitLock, M. 1993. Lack of correlation between heterozygosity and fitness in forked fungus beetle. Heredity, $\mathbf{7 0}$, 574-581.

WRIGHT, s. 1965. The interpretation of population structure by F-statistics with special regard to systems of mating. Evolution, 19, 395-420.

zouros, E. 1993. Associative overdominance: evaluating the effects of inbreeding and linkage disequilibrium. Genetics, 89, 35-46.

ZOUROS, E. AND MALLET, A. L. 1989. Genetic explanations of the growth/heterozygosity correlation in marine mollusks. In: Ryland, J. S. and Tyler, P. A. (eds) Reproduction, Genetics and Distributions of Marine Organisms, pp. 317-324. Olsen and Olsen, Fredensborg, Denmark.

zouros, E. AND POGSON, G. H. 1994. The present status of the relationship between heterozygosity and heterosis. In: Beaumont, A. R. (ed) Genetics and Evolution of Aquatic Organisms, pp. 135-146. Chapman and Hall, London.

ZOUROS, E., ROMERO-DOREY, M. AND MALLET, A. L. 1988. Heterozygosity and growth in marine bivalves: further data and possible explanations. Evolution, 42, 1332-1341.

zouros, E. AND FOLTZ, D. W. 1984. Possible explanations of heterozygote deficiency in bivalve molluscs. Malacologia, 25, 583-591.

ZOUROS, E. AND FOLTZ, D. w. 1987. The use of allelic isozyme variation for the study of heterosis. In: Rattazzi, M. C., Scandalios, J. G. and Witt, G. S. (eds) Isozymes: Current Topics in Biological and Medical Research, 13, pp. 1-59. Liss, New York. 